\title{
Pengetahuan Ibu Hamil Trimester III tentang Perawatan Payudara di Klinik Pratama Bina Sehat Kasihan, Bantul, Yogyakarta
}

\author{
Luvita Sari $^{1}$, Susi Ernawati ${ }^{2}$
}

1,2Sekolah Tinggi Ilmu Kesehatan Alma Ata Yogyakarta

Jalan Ringroad Barat Daya No 1 Tamantirto, Kasihan, Bantul, Yogyakarta

\begin{abstract}
Abstrak
Saat ini banyak ibu menyusui yang mengalami mastitis dan puting susu lecet. Puting susu lecet terjadi karena kondisi puting yang jarang dibersihkan dan posisi menyusui yang salah. Demi keberhasilan menyusui, payudara memerlukan perawatan sejak dini secara teratur agar produksi ASI cukup. Hasil wawancara diketahui bahwa 4 ibu hamil tidak mengetahui cara melakukan perawatan payudara dengan benar, dan 3 ibu hamil hanya sebatas mengetahui tetapi tidak pernah melaksanakan perawatan payudara karena merasa tidak ada kelainan di payudaranya. Tujuan penelitian ini untuk mengetahui tingkat pengetahuan ibu hamil tentang perawatan payudara. Jenis penelitian yang digunakan adalah observasional, rancangan penelitian menggunakan pendekatan deskriptif kuantitatif. Populasi yang di gunakan dalam penelitian ini yaitu seluruh ibu hamil trimester III di Klinik Pratama Bina Sehat pada bulan November 2014-Januari 2015 sebanyak 250 ibu hamil. Sampel dalam penelitian ini menggunakan teknik accidental sampling dengan jumlah sampel sebanyak 71 responden. Analisa data yang digunakan adalah analisa univariat. Hasil Penelitian adalah karakteristik ibu hamil trimester III di Klinik Pratama Bina Sehat Kasihan Bantul Yogyakarta mayoritas berusia 20-35 tahun (70,4\%), berpendidikan menengah (53,5\%), tidak berkerja (60,6\%) dan memiliki paritas mutipara (47,9\%). Tingkat pengetahuan ibu hamil trimester III tentang perawatan payudara berdasarkan umur, pendidikan, pekerjaan dan paritas memiliki pengetahuan sedang yaitu $68,0 \%, 63,2 \%, 69,8 \%, 61,8 \%$. Kesimpulan tingkat pengetahuan ibu hamil tentang perawatan payudara di Klinik Pratama Bina Sehat berada pada kategori cukup.
\end{abstract}

Kata Kunci: pengetahuan, perawatan payudara

\section{Knowledge of Pregnant Women in Third Trimester and Treatment of Breast at Clinic Pratama Bina Sehat Kasihan, Bantul, Yogyakarta}

\begin{abstract}
There are many breastfeeding mothers who suffer from mastitis and nipples blister. The nipples blister happened because the condition of a nipple who rarely cleaned and incorrect position when breastfeeding. To get the succeed in breastfeeding, breast care regularly during pregnancy will conduct the increase of milk production. The purpose of this study was to know the knowledge level of pregnant women about breast care. There was an observational study with quantitative descriptive design. The populations were 250 of pregnant women third trimester at the Clinic Pratama Bina Sehat in November 2014-Januari 2015. The samples were 71 women selected by random sampling tecniques and data were analysed by univariat analysis. The results showed that most of pregnant women in third trimester at the Clinic Pratama Bina Sehat Kasihan Bantul Yogyakarta aged 20-35 year (70.4\%), graduated from senior high school (53.5\%), housewife (60.6\%) and having the parity of even multipara (47.9\%). The level of knowledge of third trimester pregnant women about breast care based on age, education, occupation and parity were $68.0 \%, 63.2 \%, 69.8 \%, 61.8 \%$ that were included in medium category. In conclusion, the knowledge levels of pregnant women about breast care at Clinic Pratama Bina Sehat were in medium category.
\end{abstract}

Keyword: knowledge, treatment of the breast

Info Artikel:

Artikel dikirim pada 12 Februari 2015

Artikel diterima pada 12 Februari 2015 


\section{PENDAHULUAN}

ASI merupakan makanan pertama, utama, dan terbaik bagi bayi yang bersifat alamiah. ASI mengandung berbagai zat gizi yang dibutuhkan dalam proses pertumbuhan dan perkembangan bayi baru lahir yang akhirnya bertujuan untuk menurunkan angka kematian pada bayi(1). Tahun 2010, empat negara ASEAN yaitu Filipina, Indonesia, Laos dan Kamboja termasuk kelompok negara yang memiliki AKB sedang yaitu 20-49 per 1.000 kelahiran hidup(2). AKB di Indonesia menurut hasil Survei Demografi dan Kesehatan Indonesia (SDKI) mencapai AKB 32 per 1.000 kelahiran hidup ditahun 2012 kurang menggembirakan dibandingkan target Renstra Kemenkes yang ingin dicapai yaitu 24 per 1.000 kelahiran hidup juga target MDG's sebesar 23 per 1.000 kelahiran hidup ditahun 2015(3). AKB di D.I. Yogyakarta menurut hasil SDKI tahun 2012 menunjukkan bahwa mempunyai angka yang relatif lebih tinggi, yaitu sebesar 25 per 1.000 kelahiran hidup (taget MDG's sebesar 23 per 1.000 kelahiran hidup pada tahun 2015). Berdasarkan hasil SDKI 2012 tersebut, maka masalah kematian bayi merupakan hal yang serius yang harus diupayakan penurunannya agar target MDG's dapat dicapai(4).

Penurunan AKB yang melambat antara tahun 2003 sampai tahun 2012 yaitu 35 per 1.000 kelahiran hidup menjadi 32 per 1.000 kelahiran hidup, memerlukan intervensi kunci seperti ASI eksklusif. Data Profil Kesehatan Indonesia (2012) persentase pemberian ASI eksklusif pada bayi 0-6 bulan di Indonesia sebesar $48,6 \%$. Persentase pemberian ASI eksklusif tertinggi terdapat di Nusa Tenggara Barat sebesar $69,84 \%$, diikuti oleh Gorontalo sebesar $67,01 \%$, dan Bali sebesar $66,94 \%$. Persentase pemberian ASI eksklusif terendah terdapat di Provinsi Papua Barat sebesar 20,57\%, diikuti oleh Sulawesi Tengah $30,41 \%$ dan Sumatera Utara sebesar $32,22 \%(3)$. Tahun 2008 cakupan ASI eksklusif di Provinsi DIY baru mencapai $39,9 \%$, menurun pada tahun 2009 yaitu sebesar 34,56\%. Tahun 2010, cakupan ASI eksklusif meningkat mencapai 40,57\% (target $80 \%$ ),sedangkan pada tahun 2011, cakupan ASI eksklusif kembali menunjukkan peningkatan menjadi $49,5 \%$. Lebih rinci, cakupan ASI eksklusif di Kabupaten Sleman sudah mencapai $\geq 60 \%$, di Gunung Kidul masih 20\%-39\%, sedangkan di kabupaten/kota Bantul masih berkisar 42,34\%(4).

Pemberian ASI secara eksklusif dapat meminimalisir banyaknya kasus kurang gizi pada anak anak berusia dibawah 2 tahun yang sempat melanda beberapa wilayah Indonesia. Pada usia tersebut, bayi memiliki masa pertumbuhan dan perkembangan yang pesat, sehingga sering diistilahkan sebagai periode emas sekaligus periode kritis(5). Berdasarkan laporan dari Survei Demografi dan Kesehatan Indonesia diusia lebih dari 25 tahun sepertiga wanita di Dunia (38\%) didapati tidak menyusui bayinya sehingga terjadi pembengkakan payudara.

SDKI tahun 2008-2009 menunjukkan bahwa $55 \%$ ibu menyusui mengalami mastitis dan puting susu lecet. Puting susu lecet terjadi karena dua faktor, yaitu karena kondisi puting yang jarang dibersihkan dan posisi ibu saat menyusui yang kurang benar, hal tersebut disebabkan kurangnya perawatan payudara selama kehamilan. Demi keberhasilan menyusui, payudara memerlukan perawatan sejak dini secara teratur. Perawatan selama kehamilan bertujuan agar selama masa menyusui kelak produksi ASI cukup, tidak terjadi kelainan pada payudara dan agar bentuk payudara tetap baik setelah menyusui(6).

Faktor yang menyebabkan seorang ibu hamil tidak melakukan perawatan payudara karena kurangnya informasi yang didapat dari tenaga kesehatan, adanya rasa takut dan malas dan ketersediaan waktu untuk melakukan perawatan payudara selama masa kehamilan dalam trimester III. Perawatan payudara sangatlah penting dilakukan pada trimester III supaya tidak terjadi komplikasi pada saat menyusui bayinya nanti(7). Pengetahuan merupakan domain yang sangat penting untuk terbentuknya tindakan seseorang (overt behavior). Pengetahuan dipengaruhi oleh pendidikan formal. Pengetahuan sangat erat hubungannya dengan pendidikan, dimana diharapkan bahwa dengan pendidikan yang tinggi, maka orang tersebut akan semakin luas pula pengetahuannya(8).

Hasil studi pendahuluan yang dilakukan pada bulan November 2014 didapatkan data ibu hamil trimester III sebanyak 7 orang. Dari hasil wawancara diketahui bahwa 4 ibu hamil tidak mengetahui cara melakukan perawatan payudara dengan benar, dan 3 ibu hamil hanya sebatas mengetahui tetapi tidak pernah melaksanakan perawatan payudara karena merasa tidak ada kelainan di payudaranya.

Tujuan penelitian ini adalah adalah untuk mengetahui tingkat pengetahuan ibu hamil tentang perawatan payudara.

\section{BAHAN DAN METODE}

Jenis penelitian yang digunakan adalah observasional. Rancangan penelitian menggunakan survey. Populasi yang digunakan dalam penelitian ini yaitu seluruh ibu hamil trimester III di Klinik Pratama Bina Sehat sebanyak 250 ibu hamil. Cara pengambilan sampel adalah dengan Accidental sampling dengan jumlah sampel sebanyak 71 responden sesuai 
dengan kriteria inklusi dan eksklusi. Analisa data dalam penelitian ini menggunakan analisa univariat. Variabel tunggal yang digunakan dalam penelitian ini adalah pengetahuan ibu hamil trimester III tentang perawatan payudara di Klinik Pratama Bina Sehat.

\section{HASIL DAN BAHASAN}

\section{Karakteristik Ibu Hamil Trimester III di Klinik Pratama Bina Sehat Kasihan Bantul Yogyakarta}

Karakteristik ibu hamil trimester III di Klinik Pratama Bina Sehat Kasihan Bantul Yogyakarta disajikan dalam Tabel 1.

Tabel 1. Karakteristik Ibu Hamil Trimester III di Klinik Pratama Bina Sehat Kasihan Bantul Yogyakarta

\begin{tabular}{lcc}
\hline Karakteristik & f & \% \\
\hline Umur & & \\
$\quad<20$ tahun & 7 & 9,9 \\
$>35$ tahun & 14 & 19,7 \\
20-35 tahun & 50 & 70,4 \\
Pendidikan & & \\
Dasar (SD dan SMP) & 22 & 31 \\
Menengah(SMA) & 38 & 53,5 \\
Tinggi(PT) & 11 & 15,5 \\
Total & 71 & 100 \\
Pekerjaan & & \\
Bekerja & 28 & 39,4 \\
Tidak Bekerja & 43 & 60,6 \\
Total & 71 & 100 \\
Paritas & & \\
Grandemultipara & 6 & 8,4 \\
Multipara & 34 & 47,9 \\
Primipara & 31 & 43,7 \\
Total & 71 & 100 \\
\hline
\end{tabular}

Sumber: Data Primer Tahun 2014

Hasil penelitian menunjukkan bahwa sebagian besar responden berusia 20-35 tahun yaitu sebanyak 50 responden $(70,4 \%)$, berpendidikan menengah sebanyak 38 responden $(53,5 \%)$, tidak bekerja sebanyak 43 responden $(60,6 \%)$ dan memiliki paritas multipara sebanyak 34 responden $(47,9 \%)$.

Umur merupakan salah satu hal yang penting dalam mempengaruhi pengetahuan seseorang. Semakin tinggi umur seseorang semakin tinggi pula tingkat pengetahuannya dan ini diperoleh dari pengalamannya. Hal ini akan berpengaruh terhadap tindakan yang akan dilakukan oleh seseorang(9).

Hasil penelitian ini sejalan dengan penelitian dengan judul gambaran perawatan payudara pada ibu menyusui di Dusun Papak Yogyakarta. Hasil penelitian yang didapatkan adalah sebagian besar responden yang digunakan sebagai penelitian adalah ibu yang berusia 20-35 tahun(10).

Sebagian besar responden yang berpendidikan menengah sebanyak 38 responden $(53,5 \%)$. Hal ini disebabkan responden yang berada di sekitar wilayah Klinik Pratama Bina Sehat banyak yang mengikuti program pemerintah untuk dapat melanjutkan pendidikan 12 tahun yaitu pada tingkat sekolah menengah atas (SMA sederajat). Pendidikan adalah proses tumbuh kembang seluruh kemampuan dan perilaku manusia melalui pengajaran, sehingga dalam penelitian itu perlu dipertimbangkan umur dan proses belajar. Tingkat pendidikan juga merupakan salah satu faktor yang mempengaruhi persepsi seseorang untuk lebih menerima ide-ide dan teknologi yang baru. Semakin meningkat pendidikan seseorang, maka akan bertambah pengalaman yang mempengaruhi wawasan dan pengetahuan. Adapun tujuan yang hendak dicapai melalui pendidikan adalah untuk mengubah pengetahuan (pengertian, pendapat, konsep-konsep), sikap dan persepsi serta menanamkan tingkah laku atau kebiasaan yang baru(11).

Hasil penelitian ini sejalan dengan penelitian dengan judul gambaran perawatan payudara pada ibu menyusui di Dusun Papak Yogyakarta. Hasil penelitian yang didapatkan adalah sebagian besar responden yang digunakan sebagai penelitian adalah ibu yang berpendidikan menengah keatas (SMA)(10).

Sebagian besar responden yang tidak bekerja sebanyak 43 responden $(60,6 \%)$. Hal ini disebabkan sebagian besar penduduk wanita yang berada di sekitar Klinik merupakan ibu rumah tangga dan yang melakukan pekerjaan adalah suami. Pekerjaan adalah aktivitas yang dilakukan sehari-hari.Seluruh bidang pekerjaan umumnya di perlukan adanya hubungan sosial dan hubungan dengan orang baik. Setiap orang harus dapat bergaul dengan orang lain, setiap orang harus bergaul dengan teman sejawat maupun berhubungan dengan atasan, maka semakin banyak informasi yang didapat untuk menambah pengetahuan seseorang. Pekerjaan dapat menggambarkan tingkat kehidupan seseorang karena dapat mempengaruhi sebagian aspek kehidupan seseorang termasuk pemeliharaan kesehatan. Dinyatakan bahwa jenis pekerjaan dapat berperan dalam pengetahuan(11).

Hasil penelitian ini sejalan dengan penelitian dengan judul gambaran perawatan payudara pada ibu menyusui di Dusun Papak Yogyakarta. Hasil penelitian yang didapatkan adalah sebagian besar responden yang digunakan sebagai penelitian adalah ibu tidak bekerja atau ibu rumah tangga(10).

Sebagian besar responden yang memiliki paritas multipara sebanyak 34 responden $(47,9 \%)$. 
Paritas adalah jumlah anak yang pernah dilahirkan oleh seorang ibu. Seorang ibu dengan bayi pertamanya mungkin akan mengalami masalah ketika menyusui dikarenakan tidak megetahui cara menyusui dengan benar. Apabila ibu mendengar dan memiliki pengalaman menyusui yang kurang baik maka akan membuat ibu merasa takut untuk memberikan ASI kepada bayinya sehingga ibu yang telah melahirkan sebelumnya akan rutin melakukan perawatan payudara agar pada kelahiran anak selanjutnya masalah dalam menyusui tidak dirasakan kembali(12).

Hasil penelitian ini sejalan dengan penelitian dengan judul hubungan perawatan payudara dengan terjadinya bendungan ASI pada ibu menyusui di Kecamatan Pasawahan Kabupaten Purwakarta Tahun 2012. Hasil penelitian yang didapatkan sebagian besar responden yang melakukan perawatan payudara adalah responden dengan paritas multipara(13).

\section{Tingkat Pengetahuan Ibu Hamil tentang Perawatan Payudara Berdasarkan Umur Ibu}

Distribusi frekuensi tingkat pengetahuan ibu hamil tentang perawatan payudara berdasarkan umur ibu di Klinik Pratama Bina Sehat Kasihan Bantul Yogyakarta disajikan dalam Tabel 2.

Tabel 2. Tingkat Pengetahuan Ibu Hamil tentang Perawatan Payudara Berdasarkan Umur Ibu

\begin{tabular}{lcccccccc}
\hline \multirow{2}{*}{$\begin{array}{l}\text { Umur } \\
\text { (Tahun) }\end{array}$} & \multicolumn{4}{c}{ Pengetahuan } & \multirow{2}{*}{ Total } \\
\cline { 2 - 7 } & \multicolumn{2}{c}{ Rendah } & \multicolumn{2}{c}{ Sedang } & \multicolumn{2}{c}{ Tinggi } & & \\
\hline & $\mathbf{n}$ & $\%$ & $\mathbf{n}$ & $\%$ & $\mathbf{n}$ & $\%$ & $\mathbf{n}$ & $\%$ \\
\hline 20 & 1 & 14,3 & 4 & 57,1 & 2 & 28,6 & 7 & 100 \\
$20-35$ & 8 & 16,0 & 34 & 68,0 & 8 & 16,0 & 50 & 100 \\
$>35$ & 2 & 14,3 & 6 & 42,9 & 6 & 42,9 & 14 & 100 \\
Total & 11 & 15,5 & 44 & 62 & 16 & 22,5 & 71 & 100 \\
\hline
\end{tabular}

Sumber: Data Primer Tahun 2014

Tabel 2 menunjukkan bahwa pada kelompok umur $<20$ tahun sebagian besar memiliki pengetahuan sedang dengan jumlah 4 responden $(57,1 \%)$, pada kelompok umur 20-35 tahun sebagian besar memiliki pengetahuan sedang dengan jumlah 34 responden
$(68,0 \%)$, dan pada kelompok usia $>35$ tahun sebagian besar memiliki pengetahuan sedang dan tinggi dengan jumlah 6 responden $(42,9 \%)$.

Umur ibu sangat menentukan kesehatan maternal karena berkaitan dengan kondisi kehamilan, persalinan dan nifas, serta cara mengasuh juga menyusui bayinya. lbu yang berumur kurang dari 20 tahun masih belum matang dan belum siap secara jasmani dan sosial dalam menghadapi kehamilan, persalinan serta dalam membina bayi yang di lahirkan(14).

Ibu yang berumur 20-35 tahun, menurut Hurlock disebut sebagai "masa dewasa" dan disebut juga masa reproduksi, dimana pada masa ini diharapkan orang telah mampu untuk memecahkan masalahmasalah yang dihadapi dengan tenang secara emosional, terutama dalam menghadapi kehamilan, persalinan, nifas, dan merawat bayinya nanti(9).

Kehamilan pada usia remaja 12-19 tahun harus dikaji pula secara teliti karena perkembangan fisik, psikologi, maupun sosialnya belum siap sehingga dapat menggangu keseimbangan psikologis dan dapat mempengaruhi produksi ASI. Dengan bertambahnya umur, maka akan semakin bertambah pula pengetahuan responden sehingga responden akan lebih mengetahui bagaimana cara melakukan perawatan payudara.

Hasil penelitian ini sejalan dengan penelitian yang dilakukan oleh Ririn dengan judul hubungan umur ibu hamil dengan kepatuhan ibu dalam melakukan perawatan payudara selama kehamilan di BPS Dini Melanie. Hasil penelitian menunjukkan bahwa terdapat hubungan antar umur ibu hamil dengan kepatuhan ibu dalam melakukan perawatan payudara selama kehamilan(15). Ibu yang berusia 20-35 tahun merupakan usia dimana seorang ibu hamil aktif mencari informasi mengenai kehamilannya termasuk mengenai cara menyusui dan perawatan payudara selama kehamilan.

\section{Tingkat Pengetahuan lbu Hamil tentang Perawatan Payudara Berdasarkan Pendidikan Ibu}

Distribusi frekuensi tingkat pengetahuan ibu hamil tentang perawatan payudara berdasarkan pendidikan ibu di Klinik Pratama Bina Sehat Kasihan Bantul Yogyakarta disajikan dalam Tabel 3.

Tabel 3. Tingkat Pengetahuan Ibu Hamil tentang Perawatan Payudara Berdasarkan Pendidikan lbu

\begin{tabular}{lcccccccc}
\hline \multirow{2}{*}{ Pendidikan } & \multicolumn{9}{c}{ Pengetahuan } & \multicolumn{2}{c}{ Total } \\
\cline { 2 - 8 } & \multicolumn{2}{c}{ Rendah } & \multicolumn{2}{c}{ Sedang } & \multicolumn{2}{c}{ Tinggi } & \multicolumn{2}{c}{} \\
\cline { 2 - 8 } & $\mathbf{n}$ & $\%$ & $\mathbf{n}$ & $\%$ & $\mathbf{n}$ & $\%$ & $\mathbf{n}$ & $\%$ \\
\hline Dasar (SD danSMP) & 1 & 4,5 & 16 & 72,7 & 5 & 22,7 & 22 & 100 \\
Menengah(SMA) & 7 & 18,4 & 24 & 63,2 & 7 & 18,4 & 38 & 100 \\
Tinggi(Perguruan Tinggi) & 3 & 27,3 & 4 & 36,4 & 4 & 36,4 & 11 & 100 \\
Total & 11 & 15,5 & 44 & 62,0 & 16 & 22,5 & 71 & 100 \\
\hline
\end{tabular}

Sumber: Data Primer Tahun 2014 
Tabel 3 menunjukkan bahwa pada kelompok pendidikan dasar sebagian besar memiliki pengetahuan sedang dengan jumlah 16 responden $(72,7 \%)$, pada kelompok pendidikan menengah sebagian besar memiliki pengetahuan sedang dengan jumlah 24 responden $(63,2 \%)$, dan pada kelompok pendidikan tinggi sebagian besar memiliki pengetahuan sedang dan tinggi dengan jumlah 4 responden $(36,4 \%)$.

Hal ini jelas bahwa dengan pengetahuan yang tinggi wawasan dan usaha untuk mencari informasi akan lebih luas, karena orang yang memiliki dasar pendidikan menengah dan tinggi lebih mudah mengerti dan memahami informasi yang diterimanya bila dibanding dengan respoden yang berpendidikan lebih rendah.

Penelitian ini sesuai dengan teori semakin tinggi pendidikan yang ditempuh oleh seseorang, maka semakin baik pengetahuan dan lebih luas dibandingkan dengan tingkat pendidikan yang rendah(11). Pendidikan juga akan membuat seseorang terdorong untuk ingin tahu, mencari pengalaman sehingga informasi yang diterima akan jadi pengetahuan(16).

Hasil penelitian ini sejalan dengan penelitian dengan judul gambaran pengetahuan tentang perawatan payudara selama menyusui di Desa Argomulyo. Hasil penelitian diketahui bahwa sebagian besar responden yang melakukan perawatan payudara adalah responden yang memiliki pendidikan menengah ke atas dan telah memiliki pengalaman dalam menyusui(17).

\section{Tingkat Pengetahuan Ibu Hamil tentang Perawatan Payudara Berdasarkan Pekerjaan Ibu}

Distribusi frekuensi tingkat pengetahuan ibu hamil tentang perawatan payudara berdasarkan pekerjaan ibu di Klinik Pratama Bina Sehat Kasihan Bantul Yogyakarta disajikan dalam Tabel 4.

Tabel 4. Tingkat Pengetahuan Ibu Hamil tentang Perawatan Payudara Berdasarkan Pekerjaan Ibu

\begin{tabular}{lcccccccc}
\hline & \multicolumn{4}{c}{ Pengetahuan } & \multirow{2}{*}{ Total } \\
\cline { 2 - 7 } Pekerjaan & Rendah & Sedang & \multicolumn{1}{c}{ Tinggi } & & \\
\cline { 2 - 8 } & $\mathbf{n}$ & $\%$ & $\mathbf{n}$ & $\%$ & $\mathbf{n}$ & $\%$ & $\mathbf{n}$ & $\%$ \\
\hline Bekerja & 3 & 10,7 & 14 & 50,0 & 11 & 39,3 & 28 & 100 \\
Tidak Bekerja & 8 & 18,6 & 30 & 69,8 & 5 & 11,6 & 43 & 100 \\
Total & 11 & 15,5 & 44 & 62,0 & 16 & 22,5 & 71 & 100 \\
\hline
\end{tabular}

Sumber: Data Primer Tahun 2014

Tabel 4 menunjukkan bahwa pada kelompok responden yang bekerja, memiliki pengetahuan sedang yaitusebanyak 14 responden $(50,0 \%)$ sedangkan yang tidak bekerja memiliki pengetahuan sedang yaitu sebanyak 30 responden $(69,8 \%)$.
Selain itu pekerjaan juga dapat mempengaruhi pengetahuan dalam perilaku sehari-hari. Pekerjaan adalah aktifitas yang dilakukan sehari-hari. Dimana seluruh bidang pekerjaan umumnya diperlukan adanya hubungan sosial dan hubungan dengan orang baik, setiap orang harus dapat bergaul dengan orang lain, setiap orang harus bergaul dengan teman sejawat maupun berhubungan dengan atasan, maka semakin banyak informasi yang didapatkan untuk menambah pengetahuan seseorang. Pekerjaan dapat menggambarkan tingkat kehidupan seseorang karena dapat mempengaruhi sebagian aspek kehidupan seseorang termasuk pemeliharaan kesehatan. Dinyatakan bahwa jenis pekerjaan dapat berperan dalam pengetahuan(11).

Adanya pergeseran paradigma yang dipicu oleh tingginya tingkat kebutuhan hidup dan meningkatnya pemahaman kaum wanita tentang aktualisasi diri. Pendidikan dan kebebasan informasi membuat para wanita masa kini lebih berani memasuki wilayah pekerjaan lain yang dapat memberdayakan kemampuan dirinya secara maksimal(18).

Sedangkan pada wanita yang tidak bekerja dan memiliki pengetahuan yang cukup dikarenakan wanita yang tidak bekerja lebih memiliki banyak waktu luang untuk mencari informasi di rumah mengenai perawatan payudara sehingga pengetahuan yang dimiliki kemungkinan akan meningkat(19).

Hasil penelitian ini sejalan dengan penelitian dengan judul gambaran pengetahuan tentang perawatan payudara selama menyusui di Desa Argomulyo. Hasil penelitian diketahui bahwa sebagian besar responden yang melakukan perawatan payudara adalah responden yang tidak bekerja atau sebagai ibu rumah tangga(17).

\section{Tingkat Pengetahuan Ibu Hamil tentang Perawatan Payudara Berdasarkan Paritas}

Distribusi frekuensi tingkat pengetahuan ibu hamil tentang perawatan payudara berdasarkan paritas ibu di Klinik Pratama Bina Sehat Kasihan Bantul Yogyakarta disajikan dalam Tabel 5.

Tabel 5 menunjukkan bahwa pada semua kelompok paritas memiliki pengetahuan sedang. Berturut-turut pada paritas grandemultipara, multipara dan primipara dengan jumlah 4 responden $(66,7 \%)$, 21 responden $(61,8 \%)$ dan 19 responden $(61,3 \%)$.

Ibu-ibu yang baru pertama kali hamil dan mempunyai anak memiliki masalah-masalah menyusui. Berbeda dengan ibu-ibu yang sudah menyusui sebelumnya lebih baik daripada yang pertama(20).

Paritas diperkirakan ada kaitannya dengan arah pencarian informasi tentang pengetahuan ibu dalam 
Tabel 5. Tingkat Pengetahuan Ibu Hamil tentang Perawatan Payudara Berdasarkan Paritas

\begin{tabular}{ccccccccc}
\hline \multirow{2}{*}{ Paritas } & \multicolumn{9}{c}{ Pengetahuan } & \multicolumn{2}{c}{ Total } \\
\cline { 2 - 8 } & \multicolumn{2}{c}{ Rendah } & \multicolumn{2}{c}{ Sedang } & \multicolumn{2}{c}{ Tinggi } & \multicolumn{2}{c}{} \\
\cline { 2 - 8 } & $\mathbf{n}$ & $\%$ & $\mathbf{n}$ & $\%$ & $\mathbf{n}$ & $\%$ & $\mathbf{n}$ & $\%$ \\
\hline Grandemultipara & 0 & 0,0 & 4 & 66,7 & 2 & 33,3 & 6 & 100 \\
Multipara & 4 & 11,8 & 21 & 61,8 & 9 & 26,5 & 34 & 100 \\
Primipara & 7 & 22,6 & 19 & 61,3 & 5 & 16,1 & 31 & 100 \\
Total & 11 & 15,5 & 44 & 62,0 & 16 & 22,5 & 71 & 100 \\
\hline
\end{tabular}

Sumber: Data Primer Tahun 2014

merawat payudaranya. Hal ini dihubungkan dengan pengaruh pengalaman sendiri maupun orang lain terhadap pengetahuan yang dapat mempengaruhi perilaku saat ini atau kemudian(11). Pengalaman yang diperoleh dapat memperluas pengetahuan seseorang dalam merawat payudara(21).

\section{SIMPULAN DAN SARAN}

Berdasarkan hasil penelitian mengenai gambaran pengetahuan ibu hamil Trimester III tentang perawatan payudara di Klinik Pratama Bina Sehat Kasihan Bantul Yogyakarta 2015 dapat disimpulkan bahwa: Karakteristik ibu hamil trimester III di Klinik Pratama Bina Sehat Kasihan Bantul Yogyakarta sebagian besar responden berusia 20-35 tahun yaitu sebanyak 50 responden $(70,4 \%)$, berpendidikan menengah yaitu sebanyak 38 responden $(53,5 \%)$, tidak berkerja yaitu sebanyak $43(60,6 \%)$ dan paritas mutipara yaitu sebanyak 34 responden $(47,9 \%)$. Tingkat pengetahuan ibu hamil tentang perawatan payudara berdasarkan umur ibu sebagian besar responden berumur 20-35 tahun dan memiliki pengetahuan sedang yaitu sebanyak 34 responden $(68,0 \%)$, berdasarkan pendidikan ibu sebagian besar responden memiliki pengetahuan sedang dengan pendidikan menengah yaitu sebanyak 24 responden $(63,2 \%)$, berdasarkan pekerjaan ibu sebagian besar responden memiliki pengetahuan sedang dan tidak bekerja yaitu sebanyak 30 responden $(69,8 \%)$ danberdasarkan jumlah anak dengan responden memiliki pengetahuan sedang dan memiliki paritas multipara yaitu sebanyak 21 responden $(61,8 \%)$. Perlunya menambah pengetahuan tentang bagaimana pengetahuan ibu hamil trimester III tentang perawatan payudara di Klinik Pratama Bina Sehat dan menambah referensi ilmiah bagi penelitian selanjutnya yang akan melakukan penelitian serupa. Perlunya meningkatkan wawasan bagi penulis tentang gambaran pengetahuan ibu hamil trimester III tentang perawatan payudara. Perlunya melakukan pendekatan edukatif kepada masyarakat khususnya ibu hamil trimester III tentang cara perawatan payudara.

\section{RUJUKAN}

1. Prasetyono DS. ASI Eksklusif Pengenalan, Praktik dan kemanfaatannya. Yogyakarta: Diva Press; 2005.

2. Kemenkes RI. Profil Kesehatan Indonesia Tahun 2012. Jakarta: Depkes RI; 2013.

3. Kemenkes RI. Profil Kesehatan Indonesia Tahun 2011. Jakarta: Depkes RI; 2012.

4. Dinkes DIY. Profil Kesehatan Propinsi DIY Tahun 2012. Yogyakarta: Dinkes DIY; 2013.

5. Depkes RI. Strategi Nasional Peningkatan Pemberian ASI tahun 2001-2005. Makalah disampaikan pada Workshop Peningkatan Pemberian ASI. Jakarta; 2006.

6. SDKI. Laporan Pendahuluan Survei Demografi Kesehatan Indonesia. Kemenkes RI; 2010.

7. Rustamaji. Epidemiologi dan Klinik Penyakit Tidak Menural. Jakarta: Majalah Kesehatan Masyarakat Indonesia; 2008.

8. WawanA, Dewi M. Pengetahuan, Sikap dan Perilaku Manusia. Yogyakarta: Nuha Medika; 2011.

9. Hurlock EB. Psikologi Perkembangan: Suatu Pendekatan Sepanjang Rentang Kehidupan. 5th ed. Jakarta: Erlangga; 2005.

10. Ratih. Gambaran perawatan payudara pada ibu menyusui di Dusun Papak Yogyakarta. Jurnal Kesehatan. 2013;5(12).

11. Notoatmodjo S. Ilmu Perilaku Kesehatan. Jakarta: Rineka Cipta; 2010.

12. Perinasaria. Melindungi, Meningkatkan dan Mendukung Menyusui. Cetakan Ke-4. Jakarta: Bina Rupa Akasara; 2010.

13. Ningsih. Hubungan perawatan payudara dengan terjadinya bendungan ASI pada ibu menyusui di Kecamatan Pasawahan Kabupaten Purwakarta Tahun 2012. Jurnal Kesehatan; 2012.

14. Depkes RI. Modul Pelatihan Manajemen Laktasi, Direktorat Bina Gizi Masyarakat. Jakarta; 2010.

15. Ririn. Hubungan umur ibu hamil dengan kepatuhan ibu dalam melakukan perawatan payudara selama kehamilan di BPS Dini Melanie. 2013;5.

16. Azwar A. Asuhan Persalinan Normal dan Inisiasi Menyusui Dini. Jakarta: JNPK-KR; 2006. 
17. Lestari. Gambaran pengetahuan tentang perawatan payudara selama menyusui di Desa Argomulyo. Mahasiswa Universitas Respati Yogyakarta; 2012.

18. Wulansari E. Gambaran perawatan payudara pada ibu hamil di BPS Dini Melanie Condong Catur. UNRIYO; 2012.
19. Kemenkes RI. Profil Kesehatan Indonesia Tahun 2012. Jakarta: Depkes RI; 2013.

20. Madjid. Panduan Lengkap Kehamilan, Melahirkan dan Bayi. Jakarta: ARCAN; 2006.

21. Andrianny. Faktor-faktor yang Berperan dalam Kegagalan Praktik Pemberian ASI Eksklusif. Jurnal Kesehatan. 2007;02(12):1-9. 